\title{
Small RNA Regulators and the Bacterial Response to Stress
}

\author{
S. Gottesman, * C.A. McCullen, ${ }^{*}$ M. Guillier, ${ }^{*}$ C.K. Vanderpool, ${ }^{\dagger}$ N. Majdalani, ${ }^{*}$ \\ J. Benhammou, ${ }^{*}$ K.M. Thompson, ${ }^{*}$ P.C. FitzGerald, ${ }^{+}$N.A. Sowa, ${ }^{*}$ and D.J. FitzGerald* \\ *Laboratory of Molecular Biology, Center for Cancer Research, National Cancer Institute, \\ Bethesda, Maryland 20892; Genome Analysis Unit, Center for Cancer Research, \\ National Cancer Institute, Bethesda, Maryland 20892
}

\begin{abstract}
Recent studies have uncovered dozens of regulatory small RNAs in bacteria. A large number of these small RNAs act by pairing to their target mRNAs. The outcome of pairing can be either stimulation or inhibition of translation. Pairing in vivo frequently depends on the RNA-binding protein Hfq. Synthesis of these small RNAs is tightly regulated at the level of transcription; many of the well-studied stress response regulons have now been found to include a regulatory RNA. Expression of the small RNA can help the cell cope with environmental stress by redirecting cellular metabolism, exemplified by RyhB, a small RNA expressed upon iron starvation. Although small RNAs found in Escherichia coli can usually be identified by sequence comparison to closely related enterobacteria, other approaches are necessary to find the equivalent RNAs in other bacterial species. Nonetheless, it is becoming increasingly clear that many if not all bacteria encode significant numbers of these important regulators. Tracing their evolution through bacterial genomes remains a challenge.
\end{abstract}

The bacterial genomes of organisms such as E. coli contain the information to allow the bacteria to thrive under a variety of conditions, both inside mammalian hosts and in the external environment. This requires systems to sense, respond to, and recover from a variety of stressful treatments and changes in nutrient availability. Our understanding of these systems has expanded rapidly, enhanced by the sequencing of multiple bacterial genomes. Transcriptional regulators and changes in the basic transcription machinery via use of alternative $\sigma$ factors provide appropriate regulated expression of a variety of repair and recovery genes.

In recent years, it has become increasingly clear that in addition to these transcriptional regulatory programs, stress responses also involve small regulatory RNAs that have important roles in the posttranscriptional regulation of many genes. These RNAs are frequently regulated at the level of synthesis, as part of larger regulons, and may have roles in the immediate response to stress and/or the recovery from stress. As with eukaryotic microRNAs (miRNAs) and small interfering RNAs (siRNAs), these bacterial regulatory RNAs, called sRNAs here, frequently act by pairing with specific target mRNAs to change their translation and/or stability. Other sRNAs act to influence the activity of proteins; the function of many others is still unknown (for review, see Gottesman 2004; Storz et al. 2005; Storz and Gottesman 2006) and not discussed further here. Global searches for sRNAs in E. coli, expanding studies on these RNAs and their function, and extension of findings to other bacterial species have provided us with an understanding of how these sRNAs contribute to bacterial physiology and stress responses.

\footnotetext{
†Present address: Department of Microbiology, University of Illinois, Urbana-Champaign, Ilinois 61801.
}

\section{PAIRING RNAS: MODE OF ACTION OF A "TYPICAL" BACTERIAL SMALL RNA}

The most studied and thus far most numerous family of regulatory sRNAs act by base-pairing with specific mRNAs and, in E. coli, are almost always associated with the RNA chaperone Hfq (see below). The steps in the function of sRNAs of this family are outlined in Figure 1 and discussed in some detail below.

\section{Control of Synthesis as a Primary Regulatory Step}

For any regulator, an important issue is how regulation occurs at the right time and place. For regulatory sRNAs, the primary response to environmental cues occurs at the level of synthesis. When the regulatory sRNA is made at high levels, biological effects rapidly follow. Promoters for bacterial regulatory RNAs do not differ qualitatively from promoters for protein-coding genes. However, the strength of the sRNA promoter when fully expressed and the extent of regulation may both be particularly stringent. sRNAs belong to well-characterized regulons such as those responding to oxidative stress (Altuvia et al. 1997), osmotic stress (Guillier and Gottesman 2006), and iron starvation (Massé and Gottesman 2002). Thus, the complex network of bacterial transcriptional regulators and their mechanisms for sensing cues are put to use to synthesize these sRNAs.

Some of the regulatory proteins that have been demonstrated to regulate sRNAs are summarized in Table 1. It seems likely that other global regulators will also prove to include noncoding RNAs in their regulons. Only SgrR, newly discovered via its role in regulating the sRNA SgrS (Vanderpool and Gottesman 2004), has not been found to control a large regulon in addition to the sRNA (C. Vanderpool and S. Gottesman, in prep.). The genes encoding SgrR, as well as the LysR family regulators 


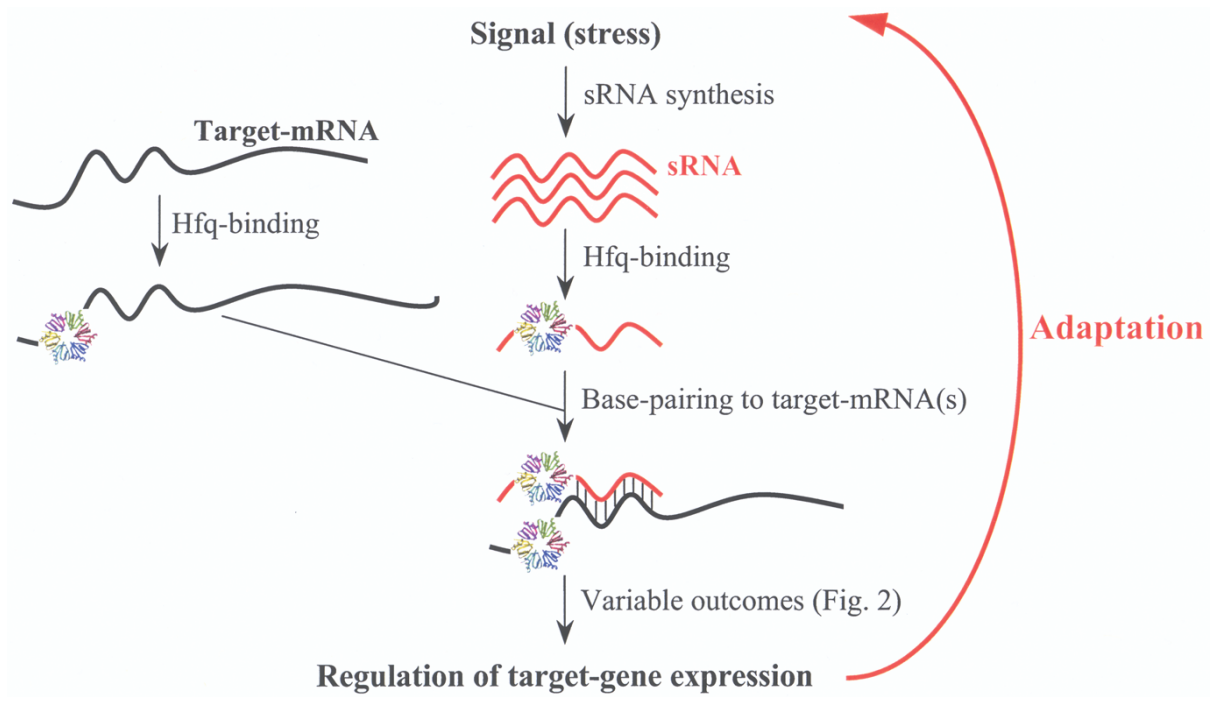

Figure 1. Cycle of activity of Hfq-dependent regulatory RNAs.

GcvA and OxyR, are next to but transcribed divergently from the sRNA that they regulate. The intergenic regions encoding the promoters and regulatory sites for the transcriptional regulator and sRNA thus overlap, allowing coordinate regulation of the regulatory protein and the sRNA, and this suggests the possibility of coevolution during any horizontal transfer events. In all the other cases listed in Table 1, the regulatory proteins and regulated noncoding RNAs are encoded far from each other.

A given regulatory protein can regulate more than one sRNA. $\sigma^{\mathrm{E}}$ controls expression of the apparently unrelated sRNAs MicA and RybB (Table 1). There are a number of examples of closely related RNAs, presumably evolved through duplication events, whose synthesis is controlled

Table 1. Regulatory Circuits with Hfq-dependent Small RNAs

\begin{tabular}{|c|c|c|c|c|c|}
\hline $\begin{array}{l}\text { Regulatory } \\
\text { protein } \\
\text { family }\end{array}$ & $\begin{array}{l}\text { Regulatory } \\
\text { protein }\end{array}$ & $\begin{array}{l}\text { Inducing } \\
\text { signal }\end{array}$ & $\begin{array}{l}\text { Small } \\
\text { RNAs }^{\text {a }}\end{array}$ & Targets $^{b}$ & References \\
\hline \multirow[t]{2}{*}{ LysR } & OxyR & oxidative stress & OxyS & $\begin{array}{l}f h l A ; y o b F \\
\quad w r b A, y b a Y\end{array}$ & $\begin{array}{l}\text { Altuvia et al. (1997); Argaman } \\
\text { and Altuvia (2000); Tjaden et } \\
\text { al. (2006) }\end{array}$ \\
\hline & GcvA & & GevB & $d p p, o p p$ & $\begin{array}{l}\text { Urbanowski et al. (2000); } \\
\text { McArthur et al. (2006) }\end{array}$ \\
\hline \multirow[t]{3}{*}{ Two-component } & OmpR & osmotic shock & OmrA, OmrB & $\begin{array}{l}\text { omp } T, \operatorname{cir} A, \\
\text { other cell } \\
\text { surface genes }\end{array}$ & Guillier and Gottesman (2006) \\
\hline & ResB & cell surface stress & RprA & rpos & Majdalani et al. (2001) \\
\hline & LuxO & quorum sensing & Qrr1-4 (Vc) & hapR & Lenz et al. (2004) \\
\hline \multirow[t]{2}{*}{ Sigma factor } & \multirow[t]{2}{*}{ Sigma E } & \multirow[t]{2}{*}{ periplasmic stress } & MicA & ompA & $\begin{array}{l}\text { Udekwu et al. (2005); Johansen } \\
\text { et al. (2006) }\end{array}$ \\
\hline & & & RybB & $\operatorname{sig} E$ & $\begin{array}{l}\text { Johansen et al. (2006); K. } \\
\text { Thompson and S. Gottesman } \\
\text { (in prep.); Vogel and } \\
\text { Papenfort (2006) }\end{array}$ \\
\hline Fur repressor & Fur & iron limitation & $\begin{array}{l}\text { RyhB }(\mathrm{Ec})(\mathrm{Vc}) \\
\operatorname{PrrF}(\mathrm{Pa})\end{array}$ & $\begin{array}{l}\operatorname{sod} B, \text { sdh, iron- } \\
\text { binding } \\
\text { proteins }\end{array}$ & $\begin{array}{l}\text { Massé and Gottesman (2002); } \\
\text { Wilderman et al. (2004); } \\
\text { Davis et al. (2005); Mey et al. } \\
(2005)\end{array}$ \\
\hline Mar family & Mar, SoxS, Rob & $\begin{array}{l}\text { oxidative stress, } \\
\text { antibiotic stress }\end{array}$ & $\mathrm{MicF}^{\mathrm{c}}$ & ompF & Delihas and Forst (2001) \\
\hline \multicolumn{2}{|c|}{ Sugar binding, novel SgrR } & $\begin{array}{l}\text { glucose-phosphate } \\
\text { accumulation }\end{array}$ & SgrS & ptsG & $\begin{array}{l}\text { Vanderpool and Gottesman } \\
\text { (2004) }\end{array}$ \\
\hline CRP & CRP & glucose limitation & Spot 42 & $\operatorname{galK}$ & Møller et al. (2002a) \\
\hline
\end{tabular}

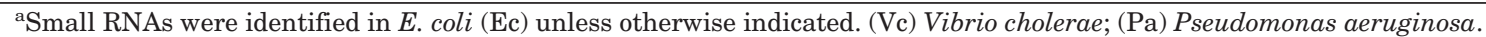

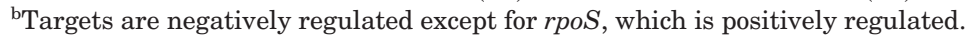

${ }^{\mathrm{c}} \mathrm{MicF}$ has also been reported to be regulated by OmpR under some conditions (Ramani et al. 1994). 
by the same regulatory protein, including the four Qrr RNAs in Vibrio cholerae, the duplicate PrrF RNAs in Pseudomonas, and OmrA and B in E. coli. Duplicated RNAs may have evolved somewhat different targets, or their synthesis may respond with different thresholds to inducing signals.

The primary transcript of the sRNA is generally active for regulation, without any requirement for processing, in contrast to the essential processing steps for microRNAs in eukaryotic cells (for review, see Cullen 2004; Gottesman 2005). Although processed transcripts are sometimes seen (Argaman et al. 2001; Repoila and Gottesman 2001; Sledjeski et al. 2001; Vogel et al. 2003; Opdyke et al. 2004), there is little information that addresses whether these are active or, if active, whether processing is essential for activity. In immunoprecipitation experiments with the RNA chaperone Hfq, the primary transcript is found to bind this protein (see below) (Wassarman et al. 2001; Zhang et al. 2003).

Finding the regulators of a small RNA. Given that the major regulatory step for most sRNAs is at the level of transcription, identifying the transcriptional regulators that control sRNA expression is a key step to understanding the physiological importance of the sRNA. Analysis of expression of the RNA by northern blot under various growth conditions is frequently the first step; computational approaches or other methods may provide clues to conditions to test (see, e.g., Massé and Gottesman 2002; Johansen et al. 2006). For more precise information, or in the absence of clues, the same sorts of approaches that can be used to define the promoters of any gene can be used to find regulators of these RNAs-deletion analysis of promoters using transcriptional fusions, and genetic screens and selections using the fusions to define transacting regulators (Majdalani et al. 2002; Guillier and Gottesman 2006).

\section{Hfq Binding and the Pairing of the Regulatory Small RNAs with mRNAs}

In vivo roles of $\boldsymbol{H} \boldsymbol{f q}$. The RNA-binding protein Hfq was first identified biochemically by its role in the in vitro replication of the RNA phage $\mathrm{Q} \beta$ (Blumenthal and Carmichael 1979). Later studies of $h f q$ mutants demonstrated that cells which are devoid of Hfq grow slowly and have very low levels of RpoS (Tsui et al. 1994; Muffler et al. 1996). The finding that Hfq was also involved in the action of some sRNAs provided a possible explanation for these phenotypes (Zhang et al. 1998; Sledjeski et al. 2001).

In immunoprecipitation experiments using an anti-Hfq antibody, the sRNAs that bind and use Hfq are significantly enriched in the immunoprecipitate and can be detected even when not specifically induced (Wassarman et al. 2001; Zhang et al. 2003). This tight binding to Hfq defines the family of Hfq-binding sRNAs. In many cases, the Hfq-binding sRNAs are significantly less stable in the absence of Hfq and consequently accumulate to lower levels (Sledjeski et al. 2001; Møller et al. 2002b; Massé et al. 2003; Zhang et al. 2003; Antal et al. 2005). Thus, it is generally assumed that Hfq rapidly binds and protects
sRNAs of this class and that it is the Hfq-bound form which is active in vivo for pairing with target mRNAs (Fig. 1), but this has not been directly demonstrated.

The biological effects of these Hfq-binding sRNAs are absent in $h f q$ mutants (see, e.g., Zhang et al. 1998; Sledjeski et al. 2001; Massé and Gottesman 2002; Møller et al. 2002a). For instance, translation of the stationary-phase $\sigma$ factor, RpoS, is dramatically reduced in E. coli hfq mutants; mutations that increase translation disrupt an inhibitory hairpin in the rpoS leader mRNA (Brown and Elliott 1997). At least two sRNAs, and probably others, stimulate translation of $r p o S$ by interacting with and opening the inhibitory hairpin (for review, see Repoila et al. 2003). In an $h f q$ mutant, these sRNAs can no longer stimulate translation and RpoS is not made. Another example is provided by the phenotype of fur mutants of $E$. coli. Fur represses RyhB, and RyhB down-regulates the genes encoding succinate dehydrogenase (see below). As a result, fur mutants cannot grow on succinate. Mutations in either $r y h B$ or $h f q$ can restore growth (Massé and Gottesman 2002). $h f q$ mutants of Vibrio and Brucella are avirulent (Robertson and Roop 1999; Ding et al. 2004), and $h f q$ mutants of Vibrio and Pseudomonas have defects in the quorum sensing pathway (Lenz et al. 2004; Sonnleitner et al. 2006), although it has not been demonstrated in all of these cases that the phenotypes are due to loss of function of sRNAs and not some other role of Hfq.

In vitro activities of $\boldsymbol{H} \boldsymbol{f q}$. Rapid turnover of the regulatory sRNAs in vivo in the absence of Hfq might be a sufficient explanation for loss of function of these sRNAs, but a variety of in vitro experiments suggest that Hfq has a more direct role as an RNA chaperone. Specifically, interactions of an sRNA and target mRNA are promoted by the presence of Hfq in vitro (Møller et al. 2002b; Zhang et al. 2002; Lease and Woodson 2004; Kawamoto et al. 2006). In these and other experiments, Hfq binds the target mRNA as well as the regulatory RNA (Geissmann and Touati 2004). What proportion of the population of a given mRNA or sRNA is bound at any time has not been examined in vivo.

How does binding of Hfq to both mRNA and regulatory RNA promote pairing? Hfq subunits assemble into a hexameric ring (Fig. 1); a model oligonucleotide has been shown to bind to the inner surface of the ring, and evidence for secondary RNA-binding sites have also been described (Schumacher et al. 2002; Sauter et al. 2003; Mikulecky et al. 2004; Valentin-Hansen et al. 2004). Models depending on pairing of Hfq rings or binding of both RNAs to a single ring have been suggested (Storz et al. 2004) and may be important in stabilizing RNA:RNA interactions once they have been initiated. However, most bacterial species, including $E$. coli, encode only one $h f q$ gene; thus, Hfq must be able to promote interactions between many sRNAs that pair with different mRNAs. This implies that Hfq does not itself provide specificity of pairing. Instead, pairing may proceed more rapidly when the RNA secondary or tertiary structure is remodeled by Hfq binding (Moll et al. 2003a; Geissmann and Touati 2004; Lease and Woodson 2004; Antal et al. 2005), and, once pairing is initiated, it may be extended and/or stabilized by interactions 
with Hfq. Thus, although complementarity between the sRNA and the target mRNA may be essential for pairing (Kawamoto et al. 2006), it is apparently not sufficient in most cases. High-affinity Hfq-binding sites on both the sRNA and the target mRNA provide additional necessary elements. Computational approaches that do not take this into account may predict that pairing between sRNAs and target mRNAs would not occur in vivo.

\section{Outcomes of Pairing}

Pairing of the sRNA to its target mRNA can result in positive or negative effects on translation. In the beststudied case of stimulation of translation, two different sRNAs, DsrA and RprA, bind to counteract the formation of an inhibitory hairpin in the mRNA of $r p o S$ that blocks translation (Fig. 2A) (Majdalani et al. 1998, 2002). In many cases, negative effects are associated with the sRNA binding close to the ribosome-binding site. Binding may both inhibit translation (under conditions where mRNA degradation is blocked) and lead to rapid mRNA degradation (Morita et al. 2006) (Fig. 2B). It is not yet clear whether mRNA degradation is secondary to blocking ribosome access.

\section{Translation Inhibition and mRNA Degradation}

For most of the cases of sRNA-dependent mRNA degradation, the target message disappears rapidly (within 2-3 minutes) and completely after induction of the regulatory RNA (Massé and Gottesman 2002; Massé et al. 2005; Rasmussen et al. 2005; Udekwu et al. 2005; Guillier and Gottesman 2006); in some cases, much smaller degradation products can be detected (Morita et al. 2003; Vanderpool and Gottesman 2004). Degradation is generally due to the activity of RNase E (Massé et al. 2003; Afonyushkin et al. 2005; Morita et al. 2005). RNase $\mathrm{E}$ is an essential endonuclease that cleaves at singlestranded AU-rich RNA (for review, see Kennell 2002).
Presumably, endonucleolytic cleavage by RNase E serves as a primary step, followed by degradation by a variety of exonucleases. Absence of translation can uncover RNase E cleavage sites internal to a coding region that are otherwise inefficiently cleaved (Joyce and Dreyfus 1998; Baker and Mackie 2003; for review, see Deana and Belasco 2005). Thus, an sRNA might promote rapid degradation of a message by blocking ribosome access, thereby allowing access of RNase E to recognition sites internal to the mRNA normally masked by translating ribosomes. If this is the primary cause of degradation of mRNAs targeted by sRNAs, the absence of an internal RNase E site on a given mRNA would allow regulation of translation without degradation of that mRNA. Regulation of translation without significant mRNA degradation has been described for Spot 42 regulation of translation in the gal operon (Fig. 2B) (Møller et al. $2002 \mathrm{a}$ ), although the presence or absence of RNase E sites has not been addressed. Alternatively, the act of pairing may by itself make the mRNA accessible to RNase E, by changing the structure of the RNA. There is evidence that RNase E activity is affected by secondary structure (for review, see Kennell 2002); possibly, the paired RNAs can mimic secondary structure elements in stimulating recognition or cleavage of the mRNA. Finally, recent work suggests that Hfq and RNase E are physically associated in the cell (Morita et al. 2005). If so, the Hfq binding, which is also found to be at AU-rich single-stranded regions (for review, see Valentin-Hansen et al. 2004), may in itself recruit RNase E, bypassing the need for a high-affinity site for RNase E binding to promote efficient degradation. However, Hfq binds to both mRNA and regulatory RNA in the absence of pairing, whereas degradation is only triggered upon pairing and does not occur in the case of positive regulation. Thus, a number of aspects of the mechanism remain to be explained.

Fate of small RNA. A second issue must be considered in thinking about how sRNAs stimulate RNase-E-depen-

\section{A. Positively acting sRNAs}

\section{B. Negatively acting sRNAs}
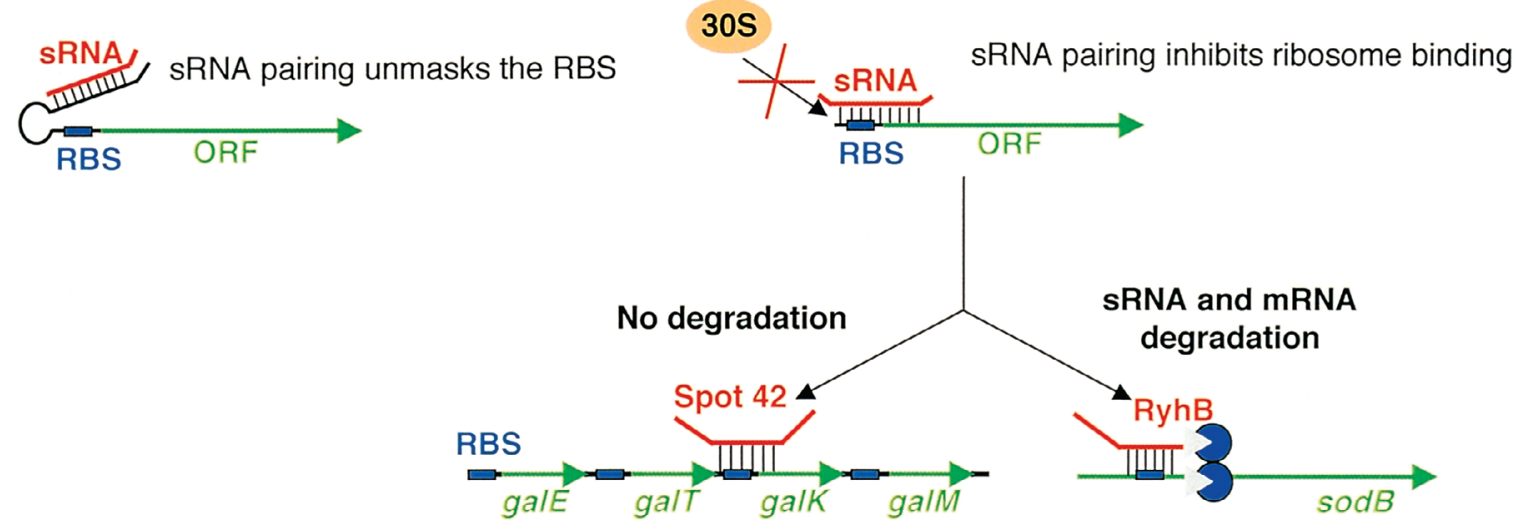

Figure 2. Outcomes of pairing for Hfq-dependent regulatory RNAs. (A) Positively acting RNAs are exemplified by DsrA and RprA action in stimulating rpoS translation (for review, see Repoila et al. 2003). (B) Negatively acting sRNAs generally pair with target mRNAs near the ribosome-binding site, but it is not yet clear what distinguishes cases where there is degradation of the mRNA (RyhB and $\operatorname{sod} B$ in the figure) and those where there is no degradation (Spot 42 and galK in the figure). 
dent cleavage. How does this pairing stimulate degradation of the regulatory RNA itself? The evidence that there is coupled degradation of the mRNA and the regulatory RNA is not yet complete, but it is nevertheless fairly compelling. A variety of sRNAs are relatively stable when turnover is measured in the presence of a general inhibitor of transcription such as rifampicin (Sledjeski et al. 2001; Vogel et al. 2003); however, the same regulatory RNAs are significantly more unstable when synthesis is shut down in a specific fashion (i.e., by turning down the promoter for the sRNA) (Massé et al. 2003). This has been interpreted to mean that the sRNA is degraded upon pairing to its target, which will be rapidly depleted after rifampicin treatment. The recruitment of RNase E by Hfq binding would provide part of the explanation for such coupled degradation, assuming, as noted above, that the act of pairing in itself helps to stimulate the degradation. RNase E endonuclease activity has been shown to be stimulated by a $5^{\prime}$ monophosphate end in vitro (Jiang and Belasco 2004). Such a 5' monophosphate would be the expected primary product of cleavage by RNase E (Kennell 2002); thus, it is possible that a cut within the mRNA may directly stimulate RNase E to cleave the paired sRNA. However, in the absence of Hfq, and therefore presumably in the absence of pairing, the sRNAs are also rapidly degraded and RNase E seems to be critical for this degradation (Massé et al. 2003), suggesting that pairing and initial cleavage of the mRNA is not the sole mechanism for RNase E to obtain access to these sRNAs. It is intriguing that Hfq and RNase E both share a preference for single-stranded AU-rich RNA. Thus, the absence of Hfq binding may uncover RNase E cleavage sites. This has been directly demonstrated in vitro for the $\operatorname{sodB}$ message and has been suggested in other cases (Moll et al. 2003b; Zhang et al. 2003; Afonyushkin et al. 2005).

Further work will be necessary to identify the basis for mRNA degradation and how translational inhibition can lead to mRNA degradation in some cases but not others. However, based on work done thus far, rapid degradation of a target mRNA is a useful and easily detectable outcome of pairing by many sRNAs, allowing the use of approaches, such as microarrays, reverse transcriptase-polymerase chain reaction (RT-PCR), as well as northern blots, to define targets for these sRNAs (discussed further below).

\section{Defining Targets}

Hfq-binding sRNAs thus far all act by complementary base-pairing to target mRNAs. Finding these targets continues to pose a challenge. Our ability to predict targets based on the expected complementarity is improving, although it still fails to find many targets (Tjaden et al. 2002). The level of false-positive predictions (good pairing predicted, but no regulation found) is also high; possibly, these potential targets do not contain Hfq-binding sites, a characteristic that is not yet integrated into search programs. It is also unclear how many targets a given sRNA will have. At least one sRNA, RyhB, has been found to regulate dozens of target mRNAs (Massé et al. 2005), whereas others have been described as regulating only one or a small number of targets (for examples of known targets, see Table 1).
One experimental approach that has been widely used is examination of the effects of sRNA expression by microarray; the success of this method depends on both detectable expression levels for the mRNA and the degradation of target mRNAs upon pairing (Davis et al. 2005; Massé et al. 2005; Mey et al. 2005; Guillier and Gottesman 2006; Tjaden et al. 2006). This approach is most likely to uncover direct rather than indirect effects if changes in mRNA levels are examined a short time (5 minutes or less) after expression of the regulatory RNA (Massé et al. 2005). Other approaches require direct interactions to capture target mRNAs, but they may be most appropriate for well-expressed messages. Affinity purification of mRNAs binding to an sRNA immobilized on a column has been successful in a number of cases (Antal et al. 2005; Douchin et al. 2006).

\section{Regulatory Steps Beyond Synthesis}

As we learn more about how the Hfq-binding sRNAs act, other possible steps for regulation of their activity, in addition to regulation of synthesis, can be identified, although most have not been fully explored. Competition for Hfq has been suggested as a mechanism for negative regulation of RpoS translation by OxyS (Zhang et al. 1998). The intrinsic stability of the sRNA will of course contribute to its accumulation, and this can be affected by Hfq binding as well. Competition between target mRNAs for a given regulatory RNA may be an important point of control if the sRNA is limiting and used stoichiometrically, which is probably the case if degradation of the sRNA is coupled with pairing. Under the strongest induction conditions, sRNA levels may not be a limiting factor. However, sRNA levels may well be limiting when there is only a basal level of induction or during recovery from an inducing stress, when synthesis of the sRNA has slowed or stopped.

\section{FINDING SMALL RNAS AND THEIR TARGETS: EXPANDING OPTIONS}

The existence of some species of sRNAs in bacteria has been known since the early days of identifying novel stable RNAs, but in many cases, their function took many years to uncover. In recent years, a combination of the availability of sequence information for many bacterial genomes and the development of microarray-based approaches for studying gene expression has allowed both computational and experimentally based discovery of many additional sRNAs and the growing understanding of their specific expression and function. Approaches for finding sRNAs have been reviewed recently (Gottesman 2004; Huttenhofer and Vogel 2006). The result of these genomewide approaches has defined more than 80 noncoding RNAs in E. coli, with at least 20 of them binding to and stabilized in vivo by Hfq (Zhang et al. 2003). Of these RNAs, studies on 14 have now been published (see Table 1).

The methods for searching for regulatory RNAs in $E$. coli have been extrapolated to other organisms. Start and stop sites are useful landmarks for some of these searches. Flanking an sRNA, one can expect to find promoter elements and/or Rho-independent terminators with a charac- 
teristic stem-loop followed by a run of U's as a stop signal. Combining conservation and the presence of a promoter and Rho-independent terminator has been developed into a program, sRNAPredict2, recently used to predict sRNAs in a variety of pathogens; a number of these predictions have been confirmed (Livny et al. 2006).

More specific predictions can be made by assuming that a stress and the physiologic response mediated by an sRNA are conserved from one species to another. Under such conditions, one can search for the regulatory sites, in combination with a terminator, for instance, within a given intergenic region. Quorum sensing sRNAs were identified in Vibrio by this approach (Lenz et al. 2004), as were ironregulated sRNAs, described below.

\section{Regulating Iron Homeostasis with Small RNAs}

All organisms, from bacteria to mammals, need to carefully regulate their intracellular iron $(\mathrm{Fe})$ pools. Iron is an essential cofactor for many enzymes; at the same time, iron can be quite toxic, causing damage to proteins and nucleic acids (Imlay 2003). Therefore, organisms generally need to minimize the accumulation of free iron. Iron acquisition may be regulated so that intracellular iron is kept to the minimum needed to satisfy requirements, and iron storage systems that sequester excess iron exist in all organisms. It has been known for decades that iron storage is regulated in mammalian cells by an intriguing posttranscriptional mechanism, in which the aconitase enzyme, an iron-binding enzyme of the TCA cycle, also acts as a regulator, binding an RNA element at the 3 ' end of some mRNAs to both positively and negatively regulate translation (Rouault 2002).

Bacteria inside mammalian hosts need to obtain iron from their host, therefore requiring that they develop methods for iron acquisition that can effectively compete for bound iron with the host. The Fur repressor is used by many bacteria, both gram-positive and gram-negative, to keep iron acquisition systems under control until they are needed (Hantke 2001). Fur directly binds $\mathrm{Fe}^{2+}$, and acts as a repressor only in the iron-bound form. RyhB, a small noncoding RNA made in $E$. coli, acts to regulate internal iron use by targeting for degradation the mRNAs of as many as 16 operons encoding iron-binding proteins (Massé and Gottesman 2002; Massé et al. 2005). RyhB is directly repressed by the Fur repressor and rapidly induced when iron is removed from Fur. It was proposed that RyhB helps to prioritize intracellular iron use under iron-limiting conditions by sparing iron for essential functions (Massé et al. 2005; Jacques et al. 2006), although genes involved in biofilm formation, acid resistance, and others have also been found to be regulated by $\mathrm{RyhB}$ in other organisms (Davis et al. 2005; Mey et al. 2005; Oglesby et al. 2005).

The biology underlying the use of Fur and RyhB to regulate intracellular iron utilization is likely to extend to many other bacteria as well. Is a sRNA also used in these bacteria? RyhB homologs can easily be found in other enterobacteria, including Salmonella, Shigella, Klebsiella, Photorhabdus, and Yersinia (Fig. 3, top) (Massé and Gottesman 2002). Yersinia, Photorhabdus, and Salmonella have two copies of an RNA similar to RyhB; one is in the context of the E. coli gene (location A), whereas the second copy is in a different chromosomal context (location B for Yersinia and Photorhabdus and location C for Salmonella) (Fig. 3, bottom). Evolutionary trees of these RyhB molecules suggest a possible early duplication event, to give the A and B locations; subsequently, the B copy may have been lost in E. coli and Salmonella. The RyhB at the C locus in Salmonella is the most divergent of this set and might have been acquired from elsewhere by horizontal transfer. In all cases, the RyhB homolog is preceded by a predicted Fur-binding site (not shown). Vibrio cholerae and other Vibrio species have a single $r y h B$ gene with some distinct characteristics. Although still regulated by Fur, the $\operatorname{ryh} B$ gene is in yet another genome context and is significantly longer than the $E$. coli RNA (Davis et al. 2005; Mey et al. 2005).

In organisms more evolutionarily distant from E. coli, RyhB cannot be found by sequence homology. For instance, a search of Pseudomonas aeruginosa sequences failed to reveal a sequence related to RyhB. However, pseudomonads contain a Fur repressor and have a similar requirement to regulate iron homeostasis. A computational search for a Fur-regulated sRNA (searching intergenic regions for RNA secondary structure within an appropriate distance from a Fur-binding site) revealed a pair of closely related RNAs that were shown to have a role in Pseudomonas similar to that of E. coli RyhB and have been called PrrF1 and PrrF2 (Pseudomonas regulatory RNA involving Fe) (Wilderman et al. 2004). Comparison to other pseudomonads demonstrated conservation of PrrFlike RNAs. In fact, all sequenced pseudomonads have two PrrF sRNAs, although only $P$. aeruginosa has two in tandem; the others have one at the same position as the $P$. aeruginosa sRNAs, whereas the other is elsewhere (Fig. 4). An examination of the evolution of PrrF in the pseudomonads would suggest that as for E. coli and its close relatives, PrrF duplicated at some point in the past. The second copy (Context B in Fig. 4) of PrrF may have been lost from $P$. aeruginosa; a later duplication of the remaining $\operatorname{prrF}$ gene yielded tandem genes that are more similar to each other than they are to any of the other pseudomonad PrrFs. No similarity in sequence or genome context is obvious between the PrrF sRNAs and RyhB sRNAs in E. coli or its close relatives. At least one target, $\operatorname{sod} B$, is shared by the PrrF and RyhB sRNAs (Wilderman et al. 2004).

As with RyhB in Yersinia and Salmonella, it would thus seem that multiple independent duplication events have occurred during evolution, suggesting a requirement for more than one $r y h B$ gene. Exactly why this would be is not yet clear. Mutation of one or the other P. aeruginosa $\operatorname{prr} F$ genes gives a partial phenotype in down-regulation of target mRNAs, suggesting that two may be necessary to achieve enough PrrF RNA for full control under severe iron depletion conditions (Wilderman et al. 2004). Alternatively, subtle differences in expression patterns and differences in sequences, and therefore pairing, might be driving the duplication of these loci.

It seems highly likely that the $E$. coli and pseudomonad RyhB-like RNAs are evolved from a common, unidentified ancestor. The lack of sequence homology in these RNAs between Pseudomonas and E. coli, coupled with the conservation of promoter sequences, suggests that 


\section{Context A: near yhhW or homologs of $y h h W$}

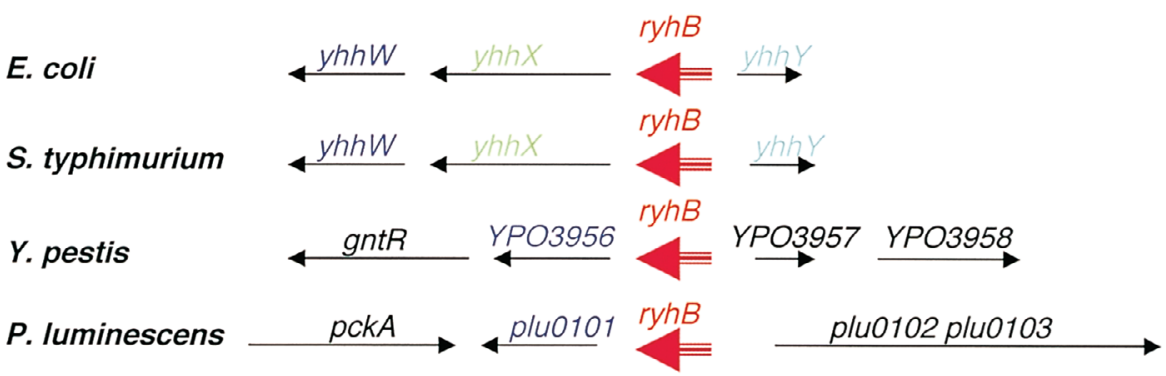

Context B: Found in Yersinia and Photorhabdus

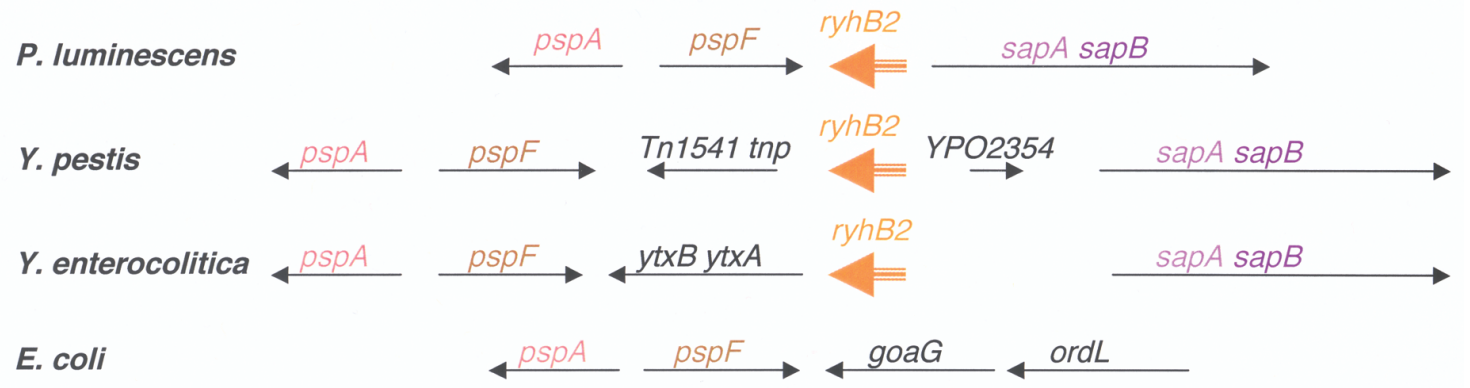

Context C: Only in Salmonella thus far

\section{S. typhimurium}

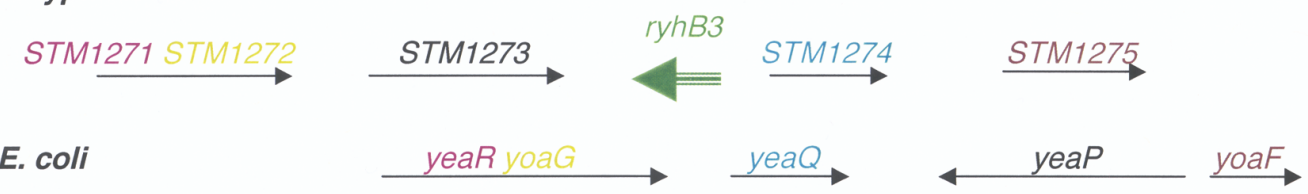

Figure 3. RyhB homologs in Enterobacteriaciae. Homologous genes are similarly color-coded. The three contexts shown are far from each other on the bacterial chromosome. We have arbitrarily named those RNAs in the same context as $E$. coli ryhB and second genes elsewhere $r y h B 2$ or $r y h B 3$ (depending on the context). These are not meant to be permanent names. Information on genes is adapted from information provided on the Comprehensive Microbial Resource of TIGR (The Institute for Genome Research [http://cmr.tigr.org/tigr-scripts/CMR/CmrHomePage.cgi; see Peterson et al. 2001).

\section{Context A}

\section{P. aeruginosa}

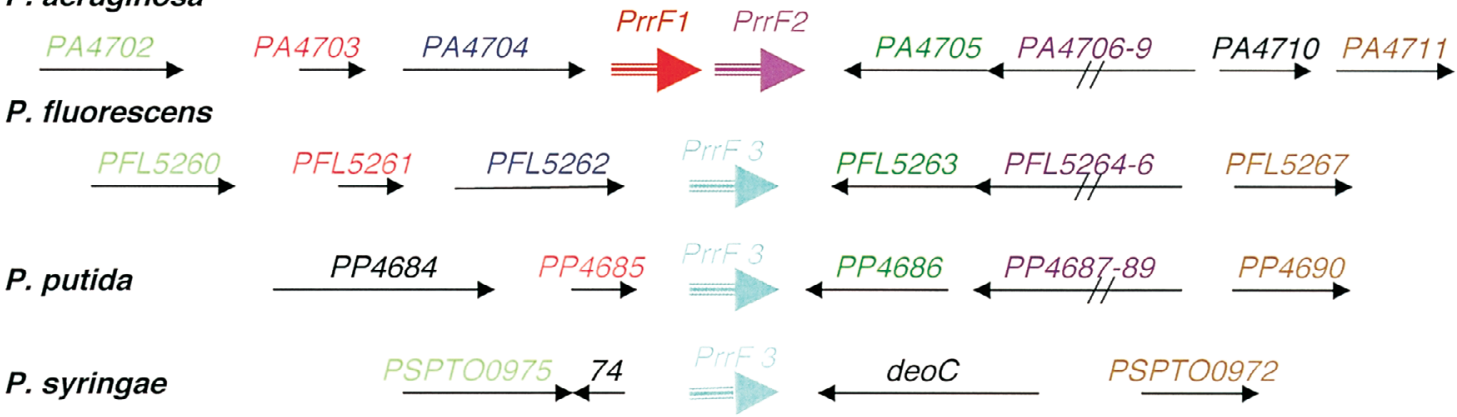

Context B

P. putida

P. syringae

P. fluorescens

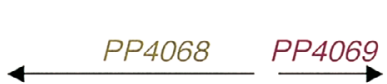

PSPTO3156
PrrF4

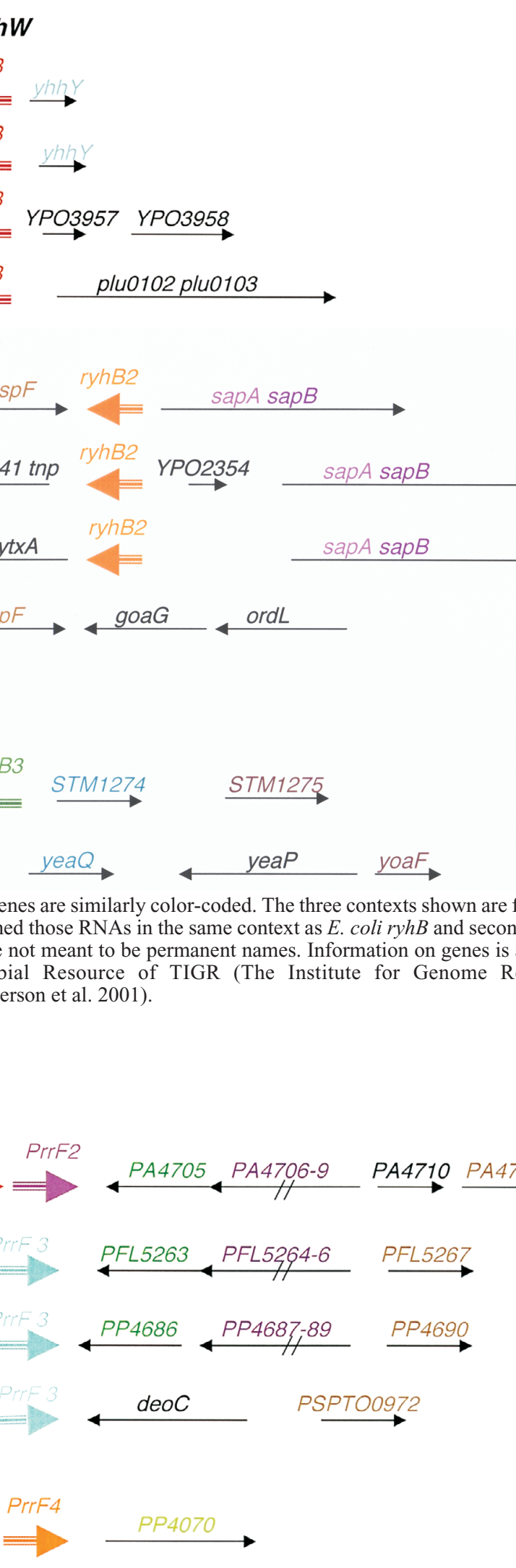



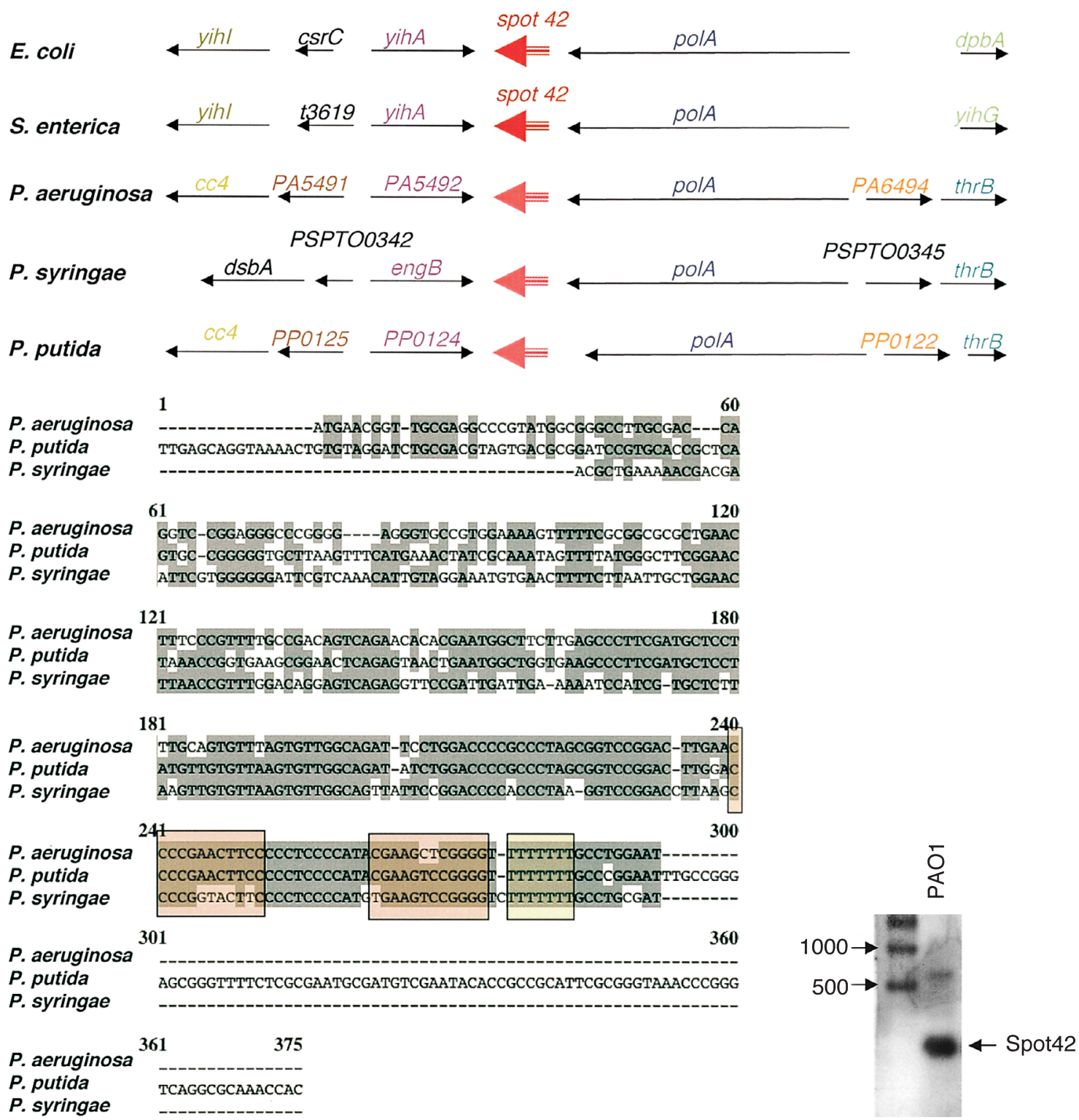

Figure 5. A possible Pseudomonas Spot 42 RNA. (Top) Conserved genome context around an sRNA in E. coli, Salmonella, and pseudomonads. Homologous genes are similarly color-coded. (polA) DNA polymerase I; (engB) GTP-binding protein. (Bottom left) Multiple sequence alignment of Pseudomonas intergenic region between polA and engB. The sequences overlapping the putative sRNAs are shown, with conserved regions in gray and the putative terminator stem-loop boxed in color. Sequences are from Genbank files AE004091 ( $P$. aeruginosa PA01), AE015451 (P. putida KT2440), and AE016853 (P. syringae pv tomato str. DC3000). Other sequenced pseudomonads are also conserved in this intergenic region. (Bottom right) Detection of a Spot 42 sRNA in $P$. aeruginosa. RNA extracted from $P$. aeruginosa strain PA01 was probed for an RNA of the sequence predicted in Figure 5 (left). The RNA isolation and northern blot procedure were carried out as described previously (Wilderman et al. 2004).

RNA genes can change relatively rapidly, possibly as their targets change or new targets are acquired. As more bacterial genomes are sequenced, it should become possible to fill in some of the missing steps and better understand how these RNAs are evolving.

\section{Genome Context as a Landmark for Small RNA Discovery}

Given the relatively rapid evolution of the RyhB-like noncoding RNAs, tracing these RNAs through evolution can be easier if a protein-coding gene can be used as a genome marker for the RNA. For instance, the E. coli $6 \mathrm{~S}$ RNA, a regulator of RNA polymerase, is processed from a longer message that includes an open reading frame $(y g f A)$ in many organisms, and by identifying the ORF, the linked but not always homologous 6S RNA was identified (and found to have a conserved structure and function) (Barrick et al. 2005; Trotochaud and Wassarman 2005).

The Hfq-binding sPRNAs have generally been found to be free-standing transcripts, not processed from a longer RNA. However, as noted above, for a few sRNAs (SgrS, 
OxyS, and GcvB), the transcriptional regulator is encoded next to and divergently from the RNA (Table 1). Thus, this protein can serve as a marker for the small RNA (McArthur et al. 2006).

\section{A Unique Genome Neighborhood for Spot 42}

A more general investigation of the genome context of the sRNAs has suggested that at least in a few cases, genes for sRNAs flanked by genes for highly conserved proteins can be found in a similar neighborhood, even when the sRNAs themselves have diverged. In particular, this appears to be the case for the genome context of the Hfqbinding Spot 42 RNA.

In E. coli, Spot 42 has been found to be responsible for polarity in the gal operon; it negatively regulates the translation of the third gene in the operon (Fig. 2B) (Møller et al. 2002a). Sequence comparisons show that Spot 42 is also present in Salmonella, Erwinia, Yersinia, and Vibrio (see RFAM; Griffiths-Jones et al. 2005).

What is notable is the genome location of this RNA (Fig. 5 , top). It is found between polA, encoding DNA polymerase I, a protein found widely in bacteria, and yihA $(\operatorname{eng} B)$, a conserved GTPase of unknown function. These two genes are also near each other in $P$. aeruginosa, and the sequences in the intergenic region are conserved in other pseudomonads and are reminiscent of those expected for a noncoding RNA (Fig. 5, bottom left). In fact, an sRNA is expressed from this locus (Fig. 5, bottom right).

As with the RyhB-like RNAs, no obvious sequence similarity can be found between Spot 42 from enterobacteria and the Pseudomonas small RNA. In addition, the gal operon, the major demonstrated target for Spot 42 in E. coli (Møller et al. 2002a), is not found in P. aeruginosa, suggesting either that this is an RNA with divergent function in the same site or that the major (conserved) function of Spot 42 has not yet been described. Further analysis of its function in Pseudomonas as well as further examination of the evolution of this and other sRNAs will clearly be fruitful.

\section{PROSPECTS FOR THE FUTURE}

Our understanding of the role of small regulatory RNAs in bacterial physiology has grown significantly over the last decade. Discoveries and approaches developed initially in E. coli are now being applied to a variety of bacteria, including pathogens. It seems highly likely that this once ignored level of regulation will provide new insights into bacterial growth and adaptation to stress and new targets for future antibiotics.

\section{ACKNOWLEDGMENTS}

The work described in this manuscript was supported by the Intramural Research Program of the National Institutes of Health, National Cancer Institute, Center for Cancer Research.

\section{REFERENCES}

Afonyushkin T., Vecerek B., Moll I., Blasi U., and Kaberdin V.R. 2005. Both RNase E and RNase III control the stability of $\operatorname{sodB}$ mRNA upon translational inhibition by the small regulatory RNA RyhB. Nucleic Acids Res. 33: 1678.

Altuvia S., Weinstein-Fischer D., Zhang A., Postow L., and Storz G. 1997. A small stable RNA induced by oxidative stress: Role as a pleiotropic regulator and antimutator. Cell 90: 43.

Antal M., Bordeau V., Douchin V., and Felden B. 2005. A small bacterial RNA regulates a putative $\mathrm{ABC}$ transporter. $J$. Biol. Chem. 280: 7901.

Argaman L. and Altuvia S. 2000. fhlA repression by OxyS RNA: Kissing complex formation at two sites results in a stable antisense-target RNA complex. J. Mol. Biol. 300: 1101.

Argaman L., Hershberg R., Vogel J., Bejerano G., Wagner E.G.H., Margalit H., and Altuvia S. 2001. Novel small RNAencoding genes in the intergenic region of Escherichia coli. Curr. Biol. 11: 941.

Baker K.E. and Mackie G.A. 2003. Ectopic RNase E sites promote bypass of $5^{\prime}$-end-dependent mRNA decay in Escherichia coli. Mol. Microbiol. 47: 75.

Barrick J.E., Sudarsan N., Weinberg Z., Ruzzo W.L., and Breaker R.R. 2005. 6S RNA is a widespread regulator of eubacterial RNA polymerase that resembles an open promoter. RNA 11: 774

Blumenthal T. and Carmichael G.G. 1979. RNA replication: Function and structure of $\mathrm{Q} \beta$-replicase. Annu. Rev. Biochem. 48: 525 .

Brown L. and Elliott T. 1997. Mutations that increase expression of the $r p o S$ gene and decrease its dependence on $h f q$ function in Salmonella typhimurium. J. Bacteriol. 179: 656.

Cullen B.R. 2004. Transcription and processing of human microRNA precursors. Mol. Cell 16: 861 .

Davis B.M., Quinones M., Pratt J., Ding Y., and Waldor M.K. 2005. Characterization of the small untranslated RNA RyhB and its regulon in Vibrio cholerae. J. Bacteriol. 187: 4005.

Deana A. and Belasco J.G. 2005. Lost in translation: The influence of ribosomes on bacterial mRNA decay. Genes Dev. 19: 2526.

Delihas N. and Forst S. 2001. MicF: An antisense RNA gene involved in response of Escherichia coli to global stress factors. J. Mol. Biol. 313: 1.

Ding Y., Davis B.M., and Waldor M.K. 2004. Hfq is essential for Vibrio cholerae virulence and downregulates $\sigma^{\mathrm{E}}$ expression. Mol. Microbiol. 53: 345.

Douchin V., Bohn C., and Bouloc P. 2006. Down-regulation of porins by a small RNA bypasses the essentiality of the RIP protease RseP in E. coli. J. Biol. Chem. 281: 12253.

Geissmann T.A. and Touati D. 2004. Hfq, a new chaperoning role: Binding to messenger RNA determines access for small RNA regulator. EMBO J. 23: 396.

Gottesman S. 2004. The small RNA regulators of Escherichia coli: Roles and mechanisms. Annu. Rev. Microbiol. 58: 273.

2005. Micros for microbes: Non-coding regulatory RNAs in bacteria. Trends Genet. 21: 399.

Griffiths-Jones S., Moxon S., Marshall M., Khanna A., Eddy S.R., and Bateman A. 2005. Rfam: Annotating non-coding RNAs in complete genomes. Nucleic Acids Res. 33: D121.

Guillier M. and Gottesman S. 2006. Remodelling of the Escherichia coli outer membrane by two small regulatory RNAs. Mol. Microbiol. 59: 231.

Hantke K. 2001. Iron and metal regulation in bacteria. Curr. Opin. Microbiol. 4: 172.

Huttenhofer A. and Vogel J. 2006. Experimental approaches to identify non-coding RNAs. Nucleic Acids Res. 2: 635.

Imlay J.A. 2003. Pathways of oxidative damage. Annu. Rev. Microbiol. 57: 395.

Jacques J.-F., Jang S., Prévost K., Desnoyers G., Desmarais M., Imlay J., and Massé E. 2006. RyhB small RNA modulates the free intracellular iron pool and is essential for normal growth during iron limitation in Escherichia coli. Mol. Microbiol. (in press).

Jiang X. and Belasco J.G. 2004. Catalytic activation of multimeric RNase E and RNase G by $5^{\prime}$-monophosphorylated RNA. Proc. Natl. Acad. Sci. 101: 9211.

Johansen J., Rasmussen A.A., Overgaard M., and ValentinHansen P. 2006. Conserved small non-coding RNAs that 
belong to the $\sigma^{\mathrm{E}}$ regulon: Role in down-regulation of outer membrane proteins. J. Mol. Biol. (in press).

Joyce S.A. and Dreyfus M. 1998. In the absence of translation, RNase E can bypass 5' mRNA stabilizers in Escherichia coli. J. Mol. Biol. 282: 241.

Kawamoto H., Koide Y., Morita T., and Aiba H. 2006. Basepairing requirement for RNA silencing by a bacterial small RNA and acceleration of duplex formation by Hfq. Mol. Microbiol. 61: 1013.

Kennell D. 2002. Processing endoribonucleases and mRNA degradation in bacteria. J. Bacteriol. 184: 4645.

Lease R.A. and Woodson S.A. 2004. Cycling of the Sm-like protein Hfq on the DsrA small regulatory RNA. J. Mol. Biol. 344: 1211.

Lenz D.H., Mok K.C., Lilley B.N., Kulkarni R.V., Wingreen N.S., and Bassler B.L. 2004. The small RNA chaperone Hfq and multiple small RNAs control quorum sensing in Vibrio harveyi and Vibrio cholerae. Cell 118: 69.

Livny J., Brencic A., Lory S., and Waldor M.K. 2006. Identification of 17 Pseudomonas aeruginosa sRNAs and prediction of sRNA-encoding genes in 10 diverse pathogens using the bioinformatic tool sRNAPredict2. Nucleic Acids Res. 34: 3484.

Majdalani N., Hernandez D., and Gottesman S. 2002. Regulation and mode of action of the second small RNA activator of RpoS translation, RprA. Mol. Microbiol. 46: 813.

Majdalani N., Chen S., Murrow J., St. John K., and Gottesman S. 2001. Regulation of RpoS by a novel small RNA: The characterization of RprA. Mol. Microbiol. 39: 1382.

Majdalani N., Cunning C., Sledjeski D., Elliott T., and Gottesman S. 1998. DsrA RNA regulates translation of RpoS message by an anti-antisense mechanism, independent of its action as an antisilencer of transcription. Proc. Natl. Acad. Sci. 95: 12462.

Massé E. and Gottesman S. 2002. A small RNA regulates the expression of genes involved in iron metabolism in Escherichia coli. Proc. Natl. Acad. Sci. 99: 4620.

Massé E., Escorcia F.E., and Gottesman S. 2003. Coupled degradation of a small regulatory RNA and its mRNA targets in Escherichia coli. Genes Dev. 17: 2374.

Massé E., Vanderpool C.K., and Gottesman S. 2005. Effect of RyhB small RNA on global iron use in Escherichia coli. $J$. Bacteriol. 187: 6962.

McArthur S.D., Pulvermacher S.C., and Stauffer G.V. 2006. The Yersinia pestis gcvB gene encodes two small regulatory RNA molecules. BMC Microbiol. 6: 52.

Mey A.R., Craig S.A., and Payne S.M. 2005. Characterization of Vibrio cholerae RyhB: The RyhB regulon and role of ryhB in biofilm formation. Infect. Immun. 73: 5706.

Mikulecky P.J., Meenakshi K., Brescia C.C., Takach J.C., Sledjeski D., and Feig A.L. 2004. Escherichia coli Hfq has distinct interaction surfaces for DsrA, rpoS and poly(A)RNAs. Nat. Struct. Mol. Biol. 11: 1206.

Moll I., Leitsch D., Steinhauser T., and Blasi U. 2003a. RNA chaperone activity of the Sm-like Hfq protein. EMBO Rep. 4: 284.

Moll I., Afonyushkin T., Vytvytska O., Kaberdin V.R., and Blasi U. 2003b. Coincident Hfq binding and RNase E cleavage sites on mRNA and small regulatory RNAs. RNA 9: 1308.

Møller T., Franch T., Udesen C., Gerdes K., and Valentin-Hansen P. 2002a. Spot 42 RNA mediates discoordinate expression of the E. coli galactose operon. Genes Dev. 16: 1696.

Møller T., Franch T., Hojrup P., Keene D.R., Bachinger H.P., Brennan R., and Valentin-Hansen P. 2002b. Hfq: A bacterial Sm-like protein that mediates RNA-RNA interaction. Mol. Cell 9: 23.

Morita T., Maki K., and Aiba H. 2005. RNase E-based ribonucleoprotein complexes: Mechanical basis of mRNA stabilization mediated by bacterial noncoding RNAs. Genes Dev. 19: 2176.

Morita T., Mochizuki Y., and Aiba H. 2006. Translational repression is sufficient for gene silencing by bacterial small noncoding RNAs in the absence of mRNA destruction. Proc. Natl. Acad. Sci. 103: 4858.
Morita T., El-Kazzaz W., Tanaka Y., Inada T., and Aiba H. 2003. Accumulation of glucose 6-phosphate or fructose 6phosphate is responsible for destabilization of glucose transporter mRNA in Escherichia coli. J. Biol. Chem. 278: 15608.

Muffler A., Fischer D., and Hengge-Aronis R. 1996. The RNAbinding protein HF-I, known as a host factor for phage Q $\beta$ RNA replication, is essential for rpoS translation in Escherichia coli. Genes Dev. 10: 1143.

Oglesby A.G., Murphy E.R., Iyer V.R., and Payne S.M. 2005. Fur regulates acid resistance in Shigella flexneri via RyhB and ydeP. Mol. Microbiol. 58: 1354.

Opdyke J.A., Kang J.-G., and Storz G. 2004. GadY, a smallRNA regulator of acid response genes in Escherichia coli. $J$. Bacteriol. 186: 6698

Peterson J.D., Umayam L.A., Dickinson T.M., Hickey E.K., and White O. 2001. The comprehensive microbial resource. Nucleic Acids Res. 29: 123.

Ramani N., Hedeshian M., and Freundlich M. 1994. micF antisense RNA has a major role in osmoregulation of OmpF in Escherichia coli. J. Bacteriol. 176: 5005.

Rasmussen A.A., Eriksen M., Gilany K., Udesen C., Franch T., Petersen C., and Valentin-Hansen P. 2005. Regulation of ompA mRNA stability: The role of a small regulatory RNA in growth phase-dependent control. Mol. Microbiol. 58: 1421.

Repoila F. and Gottesman S. 2001. Signal transduction cascade for regulation of RpoS: Temperature regulation of DsrA. $J$. Bacteriol. 183: 4012.

Repoila F., Majdalani N., and Gottesman S. 2003. Small noncoding RNAs, co-ordinators of adaptation processes in Escherichia coli: The RpoS paradigm. Mol. Microbiol. 48: 855.

Robertson G.T. and Roop R.M.J. 1999. The Brucella abortus host factor I (HF-1) protein contributes to stress resistance during stationary phase and is a major determinant of virulence in mice. Mol. Microbiol. 34: 690.

Rouault T.A. 2002. Post-transcriptional regulation of human iron metabolism by iron regulatory proteins. Blood Cells Mol. Dis. 29: 309.

Sauter C., Basquin J., and Suck D. 2003. Sm-like proteins in eubacteria: The crystal structure of the Hfq protein from Escherichia coli. Nucleic Acids Res. 31: 4091.

Schumacher M.A., Pearson R.F., Møller T., Valentin-Hansen P., and Brennan R.G. 2002. Structures of the pleiotropic translational regulator $\mathrm{Hfq}$ and an Hfq-RNA complex: A bacterial Sm-like protein. EMBO J. 21: 3546.

Sledjeski D.D., Whitman C., and Zhang A. 2001. Hfq is necessary for regulation by the untranslated RNA DsrA. J. Bacteriol. 183: 1997.

Sonnleitner E., Schuster M., Sorger-Domenigg T., Greenberg E.P., and Blasi U. 2006. Hfq-dependent alterations of the transcriptome profile and effects on quorum sensing in Pseudomonas aeruginosa. Mol. Microbiol. 59: 1542.

Storz G. and Gottesman S. 2006. Versatile roles of small RNA regulators in bacteria. In The RNA world, 3rd edition (ed. R.F. Gesteland et al.), p. 567. Cold Spring Harbor Laboratory Press, Cold Spring Harbor, New York.

Storz G., Altuvia S., and Wassarman K.M. 2005. An abundance of RNA regulators. Annu. Rev. Biochem. 74: 199.

Storz G., Opdyke J.A., and Zhang A. 2004. Controlling mRNA stability and translation with small, noncoding RNAs. Curr. Opin. Microbiol. 7: 140.

Tjaden B., Saxena R.M., Stolyar S., Haynor D.R., Kolker E., and Rosenow C. 2002. Transcriptome analysis of Escherichia coli using high density oligonucleotide probe arrays. Nucleic Acids Res. 30: 3732 .

Tjaden B., Goodwin S.S., Opdyke J.A., Guillier M., Fu D.X., Gottesman S., and Storz G. 2006. Target prediction for small, noncoding RNAs in bacteria. Nucleic Acids Res. 34: 2791.

Trotochaud A.E. and Wassarman K.M. 2005. A highly conserved 6S RNA structure is required for regulation of transcription. Nat. Struct. Mol. Biol. 12: 774.

Tsui H.-C.T., Leung H.-C.E., and Winkler M.E. 1994. Characterization of broadly pleiotropic phenotypes caused by 
an $h f q$ insertion mutation in Escherichia coli K-12. Mol. Microbiol. 13: 35

Udekwu K.I., Darfeuille F., Vogel J., Reimegard J., Holmqvist E., and Wagner E.G. 2005. Hfq-dependent regulation of OmpA synthesis is mediated by an antisense RNA. Genes Dev. 19: 2355.

Urbanowski M.L., Stauffer L.T., and Stauffer G.V. 2000. The $g c v B$ gene encodes a small untranslated RNA involved in expression of the dipeptide and oligopeptide transport systems in Escherichia coli. Mol. Microbiol. 37: 856.

Valentin-Hansen P., Eriksen M., and Udesen C. 2004. The bacterial Sm-like protein Hfq: A key player in RNA transactions. Mol. Microbiol. 51: 1525 .

Vanderpool C.K. and Gottesman S. 2004. Involvement of a novel transcriptional activator and small RNA in post-transcriptional regulation of the glucose phosphoenolpyruvate phosphotransferase system. Mol. Microbiol. 54: 1076.

Vogel J. and Papenfort K. 2006. Small non-coding RNAs and the bacterial outer membrane. Curr. Opin Microbiol. 9: 1

Vogel J., Bartels V., Tang H.H., Churakov G., Slagter-Jager J.G., Huttenhofer A., and Wagner E.G.H. 2003. RNomics in
Escherichia coli detects new sRNA species and indicates parallel transcriptional output in bacteria. Nucleic Acids Res. 31: 6435.

Wassarman K.M., Repoila F., Rosenow C., Storz G., and Gottesman S. 2001. Identification of novel small RNAs using comparative genomics and microarrays. Genes Dev. 15: 1637.

Wilderman P.J., Sowa N.A., FitzGerald D.J., FitzGerald P.C., Gottesman S., Ochsner U.A., and Vasil M.L. 2004. Identification of tandem duplicate regulatory small RNAs in Pseudomonas aeruginosa involved in iron homeostasis. Proc. Natl. Acad. Sci. 101: 9792.

Zhang A., Wassarman K.M., Ortega J., Steven A.C., and Storz G. 2002. The Sm-like Hfq protein increases OxyS RNA interaction with target mRNAs. Mol. Cell 9: 11.

Zhang A., Altuvia S., Tiwari A., Argaman L., Hengge-Aronis R., and Storz G. 1998. The oxyS regulatory RNA represses rpoS translation by binding $\mathrm{Hfq}(\mathrm{HF}-1)$ protein. EMBOJ. 17: 6061.

Zhang A., Wassarman K.M., Rosenow C., Tjaden B.C., Storz G., and Gottesman S. 2003. Global analysis of small RNA and mRNA targets of Hfq. Mol. Microbiol. 50: 1111. 


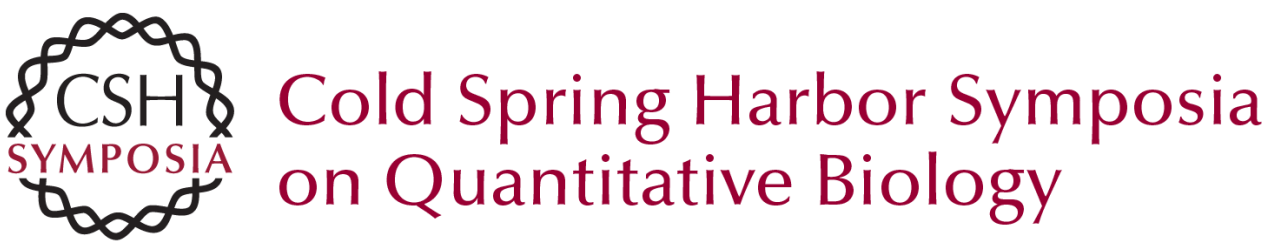

\section{Small RNA Regulators and the Bacterial Response to Stress}

S. GOTTESMAN, C.A. McCULLEN, M. GUILLIER, et al.

Cold Spring Harb Symp Quant Biol 2006 71: 1-11

Access the most recent version at doi:10.1101/sqb.2006.71.016

References This article cites 77 articles, 29 of which can be accessed free at:

http://symposium.cshlp.org/content/71/1.full.html\#ref-list-1

\section{License}

Email Alerting Receive free email alerts when new articles cite this article - sign up in Service the box at the top right corner of the article or click here. 